\title{
Effects of Cooperative Learning Method (CLM) on Vocabularies and Grammars in Essay Writing
}

\author{
Wondwosen Tesfamichael Ali \\ Department of English Language \& Literature, College of Social Sciences \& Humanities, Wolaita Sodo \\ University, Wolaita Sodo, Ethiopia \\ tesfa1959@gmail.com
}

\begin{abstract}
The target of this research was to examine whether or not the effects of CLM improved eleventh graders' essay writing skills in terms of vocabularies and grammars. The quasi-experimental research was employed and the sample population was taken from two sections of eleventh grade. The CLM was implemented in the experimental group after the students had been made to have awareness about it whereas in the control group, the students were taught their lessons based on the usual lesson plan in which the elements of the method were not used. Data were collected through pre-and post-tests. Dependent t-tests were employed to test whether or not there were significant intra-group differences on the vocabularies and grammars in essay writing skills at 0.05 risk levels whereas independent samples t-tests were used to check if there were significant inter-group differences on the vocabularies and grammars in essay writing skills at 0.05 alpha levels. The analyses of the vocabularies and grammars in essay writing skills pre-test of the inter-groups showed that both groups had similar backgrounds in writing vocabularies and grammars in essays at the initial stage of this research. Nevertheless, after the treatments had been given to the experimental research participants, the analyses of the data indicated that the experimental group outscored significantly $(p<0.05)$ the control group in writing vocabularies and grammars in essay writing post-test. This indicates that the effects of CLM brought about changes on the experimental group. Therefore, the major findings of this study reveal that the CLM enabled the participants in the experimental group to show improvements in writing vocabularies and grammars in essays.
\end{abstract}

Keywords : cooperative learning; vocabularies; grammars; writing skills; flements; english as a foreign language; Ethiopia

\section{Inroduction}

To build up the teaching learning process in general, there seems to be an increasing consensus in pedagogy worldwide to use CLM, i.e. the need to shift from a teacher-centered method of teaching (where the teacher does all the talking with students remaining passive) to a student-centered method (with students actively involved in the learning process) (Nagata \& Ronkowski, 1988).

Moffet (1996) added that CLM enables the students from a pluralistic society to overcome their prejudices against others from different backgrounds such as culture, learning style, religion, etc. In other words, CLM provides the students with opportunities to enhance inter-ethnic relations and learn to appreciate differences as their focus of attention is getting immersed when they learn writing or other skills with this method in English as a foreign language (EFL) classrooms.

Stahl and VanSickle (1992) argued that students found in very diverse school settings and taught a wide range of content areas reveal higher academic test scores, higher self-esteem and positive social skills after completing the tasks treated through CLM. Reticent students 
also get an opportunity to make new friends and familiarize different activities more easily through this method. Stenlev (2003) pointed out the positive effect of the CLM by saying that it is a democratic form of learning, i.e. every single student is required in many different contexts to adopt an attitude and explain his or her own point of view. Stenlev further explained that the students learn social skills like to listen to and respect each other, and every one can feel that they are at the center at the same time. So, according to her, it is an excellent way of conducting communicative language teaching in general and teaching vocabularies and grammars in writing skills in particular.

\section{Objective of the Study}

The objectives of this research were to examine whether or not an appropriate implementation of CLM in line with the literature could improve the experimental group participants' vocabularies and grammars while composing assorted essays.

\section{Hypotheses of the Study}

Based on the research objective, the following hypotheses were devised:

Ho1: There is no significant difference between the mean scores of the experimental and control groups on grammar and vocabulary post-test while writing essays.

Ha2: There is no significant difference between the mean scores of the experimental and control groups on grammar and vocabulary post-test while writing essays.

\section{Literature Review}

\subsection{Rationales for Using the CLM in teaching Vocabularies and Grammars}

The CLM, which has positive effects on the teaching learning process, could be applied to all language skills (Elbow, 2000). With regard to the rationales of incorporating it into vocabulary and grammar writing skills, Elbow explained that the method:

1. Forces the writer to put tacit decisions about his/her writing process into words.

2. Allows students to learn from each other as confident students will model successful writing practices for struggling students.

3. Allows students to work on complex projects which may otherwise be too large in scope for an individual to tackle over the course of the semester.

4. Fosters relationships among a community of writers as it takes away the loneliness of the writing act.

5. Focuses on the generation of many possible points of views/solutions to a problem, which ultimately leads to more complex conclusions.

Thus, to make the students users of this method, attention should be given to what they can do to initiate and manage their own vocabulary and grammar writings through cooperation. This is more feasible, according to Ingleton, et.al (2000), when teachers organize the groups instead of allowing the students to self-select. 


\subsection{Elements of CLM}

The elements of CLM are important to make cooperation proceed and work well. For the success of any CLM, Johnson, Johnson and Holubec (1993) argued that the five elements of CLM should be included in each lesson to make cooperation effective. Johnson and Johnson (1990) also stressed that the five fundamental elements of CLM are salient to distinguish them from other forms of group learning. They remarked that when all the elements of CLM are properly implemented in an EFL/ESL class, the outcome is learning together through cooperation. In addition, Cosio (1998) suggested that teachers mastering the content knowledge of the discipline they teach know and practice the main elements of CLM that lead to success.

Thus, in this study, the basic elements of CLM were embedded. The researcher employed them as components of the method to see the extent to which they were implemented when the experimental group participants were writing vocabularies and grammars in their essays in the EFL class. The elements are further discussed as follows.

\subsubsection{Positive Interdependence:}

It involves the giving of a clear task and group goal so that students believe that they sink or swim together. It is the building block and the glue that hold the group together. Trivial misbehavior issues are eliminated if positive interdependence is sufficiently strong (Johnson, Johnson and Holubec, 1993).

It occurs in a group when the students realize that it takes all members to achieve a goal (Breedon and Mosley, 1991). As in any team sport, no one player can score without the help of his/her team-mates. Similarly, in a cooperative group, the students must believe that each person's effort is needed. The success of one depends on the success of the other. With regard to this, Jonson and Johnson (2009) clarified that the positive interdependence exists when the students perceive they are linked with group mates in such a way that they cannot succeed unless they must coordinate their efforts with the efforts of their group mates to complete a task. In other words, Kirk (2005) said that there must be the presence of a "one for all and all for one" attitude. This relationship does not happen automatically but must continually be encouraged by the teacher.

\subsubsection{Face-To-Face Interaction:}

It refers to the physical set up of the groups. To obtain meaningful face-to-face interactions, the size of the groups needs to be small with two to five members (Johnson and Johnson, 1998). Students need to be clustered in a group, facing each other, in order to have the kind of interchange necessary to accomplish the task. In other words, the students are provided with abundant face-to-face interactions where they orally explain how to solve problems, teach one's knowledge to others, check for understanding, discuss concepts being learned and connect present with past learning (Tuan, 2010).

\subsubsection{Individual and Group Accountability:}

It refers to structuring a level of accountability into cooperative lessons. The group is accountable for achieving its goals, and each member must be accountable for contributing a fair share of the work toward the group goal. No one can be dependent on the work of others. The performance of each individual must be assessed and the results are given back to the 
group in order to ascertain who needs more assistance and encouragement in the course of learning (Ames and Ames, 1985)

\subsubsection{Social Skills:}

Students who have never been taught the prerequisite social skills which encompass communicating, trust building, leadership, conflict resolution, group management, giving and receiving feedback, active listening skills, etc. cannot be expected to work together effectively (Johnson, Johnson and Holubec, 1993). These skills for effective cooperative work, according to the authors, do not magically appear when lessons are being conducted. Instead, they must be taught to the students as purposefully and precisely as academic skills. Schultz (1999) argued that social skills should be explicitly taught to the students so that they could work among themselves, not only in terms of cooperation but also without hostility and without the teacher's authority. However, Johnson and Johnson (1994) warned that placing socially unskilled students in a group and telling them to cooperate does not guarantee that they have the ability to do so effectively.

Kline and Lerner (2006:539) also added, "We are not born knowing instinctively how to interact effectively with others." It is, therefore, necessary that social skills must be taught to students. Westwood (2003) and Christson (1994) shared this idea and focused on the need for direct teaching of social skills like leadership, decision-making, trust-building, communication, conflict resolution, group management and others. These skills empower the students to manage the CLM which is, concerning Johnson and Johnson (1994), inherently more complex than competitive or individualistic learning because the students have to engage simultaneously in task work (learning academic subject matter) and teamwork (functioning effectively as a group).

\subsubsection{Group Processing:}

Group processing exists when group members discuss how well they are achieving their goals and maintaining effective working relationships. Groups need to describe what member actions are helpful and unhelpful and make decisions about what behaviors to continue or change. Continuous improvement in the process of learning results from the careful analyses of how members are working together and determining how group effectiveness can be enhanced. This may take five minutes or a whole lesson; it can happen immediately after the classroom interaction or on their next meeting. Thus, during the group processing, both the teacher and the students should be equally involved (Burden and Williams, 1997).

In general, the effectiveness of the elements of CLM depends on teachers' knowledge, attitudes and practices on the elements in classroom instructions. This is to mean that, if teachers have the necessary knowledge, positive attitudes and practices on the elements and if they effectively implement the elements in the real teaching and learning process, the goals of CLM are more likely to be achieved. Therefore, unless the elements are implemented meaningfully and properly, teachers should not expect the many positive long-term results of the method. 


\section{Methodology}

\subsection{Research Design}

The present researcher has advocated the post-positivism paradigm and mixed research approach. Based on this, the study employed a quasi-experimental research design, i.e. the prepost-test comparison group design whereby one group received a treatment while the other did not receive the intervention. The quasi-experimental research design was chosen because conducting an experiment means that at least one independent variable is manipulated and its effect is measured by some dependent variables while other factors are controlled in various ways (Seliger\& Shohamy, 1989). So, the design employing comparison groups enabled the researcher to compare the treatment effects between the control and experimental groups of eleventh graders.

\subsection{Participants of the Study}

As the research participants were not assigned to the experimental and control groups on the basis of random assignment, threats to internal validity were likely to occur (Basit, 2010). These threats include selection bias, maturation, instrumentation, regression to the mean and history (Creswell, 2009). Since the experimental and control groups were given pre-post-tests, one English language teacher taught the experimental and control groups, and the experiment was made to cover the same time period for all research participants, the threats listed above are unlikely to be internal-validity problems (Ary, Jacobs and Razavien, 2002). So, the results of this quasi-experimental design are credible.

Vanderstoep and Johnston (2009) said that convenient samples often involve people whom the researcher knows or people who live close to the research site. Of the many preparatory schools found in Addis Ababa, the researcher, based on Vanderstoep and Johnston' notion, used the convenient sampling technique to choose Yekatit 12 Preparatory School for the research. This is because, the school is familiar with the researcher and situated within 'Shiro Meda' where the researcher has been living. Moreover, one preparatory school was chosen because the researcher believed that it is similar to other governmental preparatory schools in Addis Ababa concerning teachers' qualifications, number of students in the class, nature of classrooms and materials used for the teaching learning process.

For this study, grade eleven was selected because the participants in this grade might give due attention to the research better than grade twelve students who were obsessed in preparing themselves for Ethiopian Higher Education Entrance Certificate Examination. Moreover, the researcher felt that the students in the lower grade might not compose vocabularies and grammars in different types of essays in the way that they were expected to do.

One teacher was selected randomly using lottery system out of the entire 6 EFL teachers teaching 18 sections. The selected teacher covered two sections, i.e. $11^{\text {th4 }}$ and $11^{\text {th5 }}$ which were made to take vocabulary and grammar writing pre-test. Their papers were marked by the researcher and the results showed that both sections scored similar results. So, the students were assigned as control and experimental group research participants in their intact classes using lot.

During the interventions, each team in the experimental group was made to consist of five students. The teacher used heterogeneous grouping system in each team because this grouping system, with regard to Slavin (1991), refers to whole class of students of varying 
intellectual abilities or within classroom groupings where 2-5 students of varying abilities learn together. It can also be preferred because of its opportunities for peer tutoring and support. However, in the control group the research participants were taught through CLM which was not implemented in line with what the literature says and any kind of treatment was not given. In the course of the interventions, the teacher used formal, informal and cooperative base grouping types of CLM suggested by Johnson, Johnson and Holubec (1994) in the experimental group whereas this situation was not practiced in the control group.

The total number of the research participants for the study was 86 (43 in the control and 43 in the experimental groups). The teacher was trained on the implementation of CLM on vocabulary and grammar writing in EFL class for six consecutive days for $9 \mathrm{hrs}(1$ and $30 \mathrm{hrs}$ on each day and additional $2 \mathrm{hrs}$ for general reflections) and the teacher had also been given the training manual in advance to make him aware of CLM.

\section{Instruments}

Vocabulary and grammar writing tests were the instruments used to gather data for the study. Tests are useful to assess subjects' knowledge and capacity to apply this knowledge to new situations. They may require respondents to choose among alternatives, produce short answers, or write extended responses (Guba and Lincoln, 1981).

The researcher prepared vocabulary and grammar writing pre-post-tests based on Hogue and Oshima's (1991) writing tests. The essay writing tests consisted of two items, i.e. narrative and persuasive essays. Each type of essay focused on vocabulary and grammar and each of them was made to carry five marks and the total score became ten marks.

To compare the research participants' vocabulary and grammar writing abilities of the selected sections, i.e. $11^{\text {th4 }}$ and $11^{\text {th5 }}$, vocabulary and grammar writing pre-test was administered before assigning the sections to the experimental and control groups. This helped the researcher know the extent to which the students were able to write essays before the intervention. The tests comprised two different types of topics which are equivalent to one another in terms of difficulty levels and the research participants were ordered to write about the topics. Their papers were marked in terms of vocabularies and grammars. After the treatment, essay writing post-test in terms of vocabularies and grammars was administered. The post-test also consisted of two items which were similar to the issues raised in the pre-test and the research participants were informed to write about the topics. The aim the post-test was to weigh up the changes brought by the experimental group after the interventions.

The effect size was also measured using Cohen's index of effect size formula to see how strong the relationship between the variables was (Cohen, 1988). To calculate the difference between the control and experimental groups of the study, according to Coe (2002) and Elis (2010), subtract the mean of one group from the other (M1-M2) and divide the result by the standard deviation of the population from which the groups were sampled. Cohen (1988) shows the effect sizes in the following manner: $0-0.20=$ weak, $0.21-0.50=$ modest, $0.51-$ $1.00=$ moderate and $>1.00=$ strong. The results of pre-post-tests and their analyses as well are provided in the next section. 


\section{Findings}

Dependent and independent samples t-tests were applied to analyze the intra- and intergroups' scores. That is, descriptive statistics was employed to summarize the findings by describing the general tendencies in the data and the overall spread of the scores. Moreover, inferential statistics was used to attest or refute the already set research hypotheses in the study. The data were analyzed using SPSS Version 20. The results of pre-post-tests and their analyses are provided in the next section.

Table 1. Independent samples t-test results of the experimental and control groups on vocabulary and grammar writing pre-test $(\mathrm{N}=86)$

\begin{tabular}{|l|l|l|c|l|l|l|}
\hline Groups & Mean & SD & Std. Error Mean & T & df & $\begin{array}{l}\text { Sig. } \\
(2-\text { tailed })\end{array}$ \\
\hline Control & 9.54 & 2.11 & .322 & -.389 & 84 & $.698^{*}$ \\
\hline Experimental & 9.70 & 1.75 & .267 & & & \\
\hline \multicolumn{7}{rl}{$* p>0.05$ level }
\end{tabular}

Table 1. discloses a comparison of the control and experimental groups on essay writing pre-test in terms of vocabularies and grammars. The descriptive statistics in the table given above indicates that the mean score of the control group on vocabulary and grammar writing pre-test is 9.54 and that of the experimental group is 9.70. The table also shows that the standard deviations of essay writing scores for the control and experimental groups are 2.11 and 1.75, respectively.

The independent samples t-test for equality of means in the same table reveals that the pvalue is .698 which is greater than the alpha level. So, there is no statistically significant difference between the mean scores of the inter-groups on essay writing pre-test at 0.05 risk level. Moreover, the effect size for this comparison is 0.08 which shows that the difference that exists between the two groups in achieving vocabulary and grammar writing pre-test is trifling. This implies that both groups had similar backgrounds in writing vocabularies and grammars in essays at the initial stage of this research.

Table 2: Independent samples t-test results of the control and experimental groups on essay writing post-test in terms of vocabularies and grammars $(\mathrm{N}=86)$

\begin{tabular}{|l|l|l|l|l|l|l|}
\hline Groups & Mean & SD & Std. Error Mean & T & df & $\begin{array}{l}\text { Sig. } \\
(2-\text { tailed })\end{array}$ \\
\hline Control & 9.72 & 2.44 & .373 & -.3 .860 & 84 & $.000^{*}$ \\
\hline Experimental & 11.63 & 2.13 & .324 & & & \\
\hline \multicolumn{7}{|c|}{$\mathrm{p}<0.05$} \\
\hline
\end{tabular}

As can be seen from table 2, the mean score of the control group is 9.72 (std. 2.44) whereas the mean score of the experimental group is 11.63 (std. 2.13). So, the mean score of the experimental group is greater than the mean score of the control group.

Table 2 also reveals that the p-value is .000 which is smaller than the alpha level. Hence, the independent samples t-test for equality of means shows that there is statistically significant difference between the mean scores of the control and experimental groups on essay writing 
post-test with regard to vocabularies and grammars at 0.05 alpha level taking the side of the experimental group. Thus, it could be understood that the experimental group outperformed the control group in the post-test. The change might come because of the treatment offered to the experimental group. The effect size of both groups is 1.03 , which shows that the extent of the difference between the two groups in achieving essay writing post-test in terms of vocabularies and grammars is strong. In the next section, vocabulary and grammar writing prepost-tests of the control and experimental groups are described.

Table 3: Paired samples t-test results of the control group on essay writing pre-post-tests in terms of vocabularies and grammars $(\mathrm{N}=43)$

\begin{tabular}{|l|l|l|l|c|l|l|l|}
\hline Variables & Tests & Mean & SD & Std. Error Mean & T & Df & Sig.(2-tailed) \\
\hline Vocabulary & Pre & 2.02 & .83 & .127 & .206 & 42 & $.838^{*}$ \\
\cline { 2 - 7 } & Post & 2.00 & .82 & .125 & & & \\
\hline \multirow{2}{*}{ Grammar } & Pre & 1.98 & .51 & .093 & .172 & 42 & $.864^{*}$ \\
\cline { 2 - 5 } & Post & 1.95 & .79 & .120 & & & \\
\hline
\end{tabular}

As in table 3, the control group research participants' mean scores on each genre of essay writing are slightly different. As can be seen in the table, the mean scores of essay writing pretest for vocabulary and grammar are 2.02 and 1.98 correspondingly. On the other hand, the mean scores of the same group on essay writing post-test for that of vocabulary and grammar are 2.00 and 1.95, respectively. This indicates the presence of gaps in the research participants' scores on the post-test.

In the same table, the figures in the vocabulary and grammar pre-post-tests, i.e. $t=.206$, $\mathrm{df}=42, \mathrm{p}=.838$ and $\mathrm{t}=.172$, $\mathrm{df}=42, \mathrm{p}=.864$ show that there are no statistically significant differences between the mean scores of the control group at 0.05 alpha level on essay writing pre-post-tests in terms of the listed genres. The effect sizes of vocabulary and grammar essay writing pre-post-tests are 0.04 and 0.13 , respectively which means that the differences in the mean scores of each type of essay writing pre-post-tests are insignificant.

Table 4: Paired samples t-test results of the experimental group on vocabulary and grammar pre-post-tests $(\mathrm{N}=43)$

\begin{tabular}{|l|l|l|l|c|l|l|l|}
\hline Variables & Tests & Mean & SD & Std. Error Mean & T & Df & Sig.(2-tailed) \\
\hline Vocabulary & Pre & 1.81 & .66 & .101 & -3.597 & 42 & $.001^{*}$ \\
\cline { 2 - 6 } & Post & 2.23 & .68 & .104 & & & \\
\hline \multirow{2}{*}{ Grammar } & Pre & 1.98 & .51 & .078 & -2.986 & 42 & $.005^{*}$ \\
\cline { 2 - 5 } & Post & 2.35 & .65 & .099 & & & \\
${ }^{*}$ P $<0.05$ & & &
\end{tabular}

Table 4 depicts the mean scores of essay writing pre-post-tests in terms of vocabulary and grammar of the experimental group. The experimental group research participants' mean scores on the said components of essay writing pre-test are 1.81 and 1.98, respectively while the post-test results of the listed components of essay writing are 2.23 and 2.35 , consequently. All the components of essay writing in the table reflect higher scores in the post-test than in the pre-test. The standard deviations of the post-test also disclose that the research participants' 
scores have greater dispersions than that of the pre-test. Hence, the experimental group's essay writing pre-post mean scores are different.

As in the same table. the paired samples t-test of vocabulary and grammar pre-post-tests are $\mathrm{t}=-3.597$, df $=42, \mathrm{p}=.001$ and $\mathrm{t}=-2.986, \mathrm{df}=42, \mathrm{p}=.005$. These divulge that there are statistically significant differences between the mean scores of the experimental group on essay writing pre-post-tests at 0.05 alpha level in terms of the listed genres. The effect sizes of the vocabulary and grammar writing pre-post-tests are 0.52 and 0.62 , respectively which means that the differences in the mean scores of each type of essay writing pre-post-tests are moderate.

\section{Conclusions}

Based on the statistical analyses and descriptions of the findings of the study, the following conclusions are made in line with the research hypotheses of the study.

Vocabulary and grammar writing post-test results analyzed through the independent samples t-tests indicate that the experimental group significantly surpassed the control group. This occurred because the research participants in the experimental group were made to practice essay writing focusing on grammar and vocabulary through CLM in which the elements of the method were incorporated.

In other words, the social theorists suggested that when students do a given task cooperatively using methods like CLM, they can operate within one another's zone of proximal development (ZPD) (Vygotsky, 1978). Cooperative goal structure motivates individual members achieve their respective goals. This kind of learning among the research participants in the experimental group would help them use appropriate vocabularies and grammars while writing essays.

Thus, the null hypothesis that was stated as there is no statistically significant difference between the mean scores of the experimental and control groups on essay writing post-test regarding vocabularies and grammars was discarded as the difference between the mean scores of the inter-groups was significant at 0.05 alpha level.

On the whole, the LTM which was implemented in line with the literature has given opportunities to the experimental group research participants to review what they had written together, i.e. peer criticism aids students sharpen their knowledge about essay structure and grammatical rules. It also provides the students with the chance of evaluating their own work, demonstrating more confidence in writing and decreasing their apprehensions towards learning writing skills.

\section{References}

Ames, C., \& Ames, R. (1985). Research on motivation in education: Orlando: Academic Press, Inc. approaches ( $3^{\text {rd }}$ Edition.). London: Sage Publications. Inc.

Ary, D., Jacobs, L.C., \& Sorensen, C.K. (2010). Introduction to research in education ( $8^{\text {th }}$ ed.). Australia: Wadsworth, Cengage Learning.

Basit, T.N. (2010). Conducting research in education context (1st ed.). New York: Continuum International Publishing Group 
Breedon, T. \& Mosley, T. (1991). The cooperative learning companion. Nashville, Tennessee: Incentive Publications.

Burden, R., \& Williams, M. (1997). Psychology forlLanguage teachers: Social constructi-vist approach. Cambridge: CUP.

Christson, M. (1994). Cooperative learning in the EFL classroom in T. Kra (ed.). Teacher development: Making the right moves. Selected Articles from the English Teaching Forum, 1989-1993. Washington English Language Program Division.

Coe, R. (2002). Understanding, using and calculating effect size. Retrieved from: www.decd.sa .gov.au/quality

Cohen, J. (1988). Statistical power analysis for the behavioral sciences (2 ${ }^{\text {nd }}$ ed.). Hillsdale, NJ: Erlbaum.

Cosio, M. (1998). Implementation of cooperative learning in Mexican High Schools. Unpublished Doctoral Dissertation. University of Arizona: Mexico.

Creswell, J.W. (2009). Research design: A qualitative, quantitative, and mixed method

Elbow, P. (2000). Using the collage for collaborative writing. In everyone can write: Paragraphs toward a hopeful theory of writing and teaching writing. Oxford: Oxford University Press.

Elis, P.D. (2010). The essential guide to effect sizes. Cambridge: Cambridge University Press. Guba, E.G., \& Lincoln, Y.S. (1994). Competing paradigms in qualitative research. In N.K. Denzin \& Y.S. Lincoln (Eds.), Handbook of qualitative research . Thousand Oaks, CA: Sage.

Hogue, A., \& Oshima, A. and (1991). Writing academic English (2 ${ }^{\text {nd }}$ Edition.). In Brenda D. (2001). The Reader's handbook. New York: Longman.

Ingleton, C., Doube, L., Nobel, A., \& Rogers, T (2000). Leap into collaborative learning. centre for learning and professional development (CLPD). The University of Adelaide: Australia.

Johnson, D.W. \& Johnson, R.T. (1998). Cooperative learning and social interdependence theory. In R. Trindale, L., et al., (Eds.), Theory and research on small groups (. New York: Plenum, Social Psychological Applications to Social Issues, (4), 9-36.

Johnson, D.W. Johnson, R.T. and Holubec, E.J. (1993) Cooperative learning in the classroom. Alexandria: Association for supervision and curriculum development.

Johnson, D.W., \& Johnson, R.T. (1994). Learning together and alone. London: Allyn and Bacon.

Johnson, D.W., \& Johnson, R.T. (2009). An educational psychology success story: Social inerdependence theory and cooperative learning. Educational Researcher, 38(5), 365-37.

Johnson, D.W., Johnson, R.T., \& Holubec, E.J. (1994). The new circles of learning: Cooperation in the classroom and school. Boston: Association for Supervision and Curriculum Development.

Kirk, T. (2005). Enhancing teaching and learning through cooperative learning. Retrieved from http://www.aect.org.Intranet/Publications/edtech/35/35-04.html

Kline, F., \& Lerner, J. (2006). Learning disabilities and relateddisorders. Characteristics and teaching strategies (10 ${ }^{\text {th }}$ Edition.). Boston: Houghton Mifflin Company.

Moffet, J.M. (1996). Effective technique for English conversation group Washington: USA Information Agency Performance. 
Nagata, K., \& Ronkowski, S. (1998). Collaborative learning: Differences between collaborative and cooperative learning. The Office of Instructional Consultation, University of California Santa Barbara.

Schultz, A. (1999). Foreign language instruction and curriculum. The Education Digest, 64 (7), 29-37.

Seliger, H.W., \& Shohamy, E. (1989). Second language research methods. Oxford. Oxford University Press.

Slavin, R.E. (1991). Synthesis of research on cooperative learning. Educational Leadership, (48), 71-82.

Stahl, R.J. \& VanSickle, R. L. (1992). Cooperative learning in the social studies classroom: An invitation to social studies. Washington, DC: National Council for the Social Studies.

Stenlev, J. (2003). Cooperative learning in foreign language teaching. The Copenhagen Day and Evening College of Teacher Training

Tuan, L.T. (2010). English Language Teaching, (3)2. Retrieved from www.ccsenet.org/elt Infusing Cooperative Learning into an EFL Classroom. National University of Ho Chi Minh City University.

Vanderstoep, S., \& Johnston, D. (2009). Research methods for everyday life: Blending qualitative and quantitative approaches. San Francisco: John Wiley and Sons, Inc.

Vygotsky, L.S. (1978). Mind in society. Cambridge, MA: Harvard University Press.

Westwood, P. (2003). Common sense methods for children with special educational need ( $^{\text {th }}$ Ed.). London: Routledge Falmer. 